\title{
PELATIHAN PENGUASAAN SOAL UN MATA PELAJARAN BAHASA INDONESIA PADA SISWA KELAS XII SMAN 2 BANJARMASIN
}

\section{Indonesian Language Subject Practice Mastery Training for Class XII Students of SMAN 2 Banjarmasin}

\author{
Muhammad Ridha \\ Anwari* $^{*}$ \\ Istiqamah \\ Universitas Muhammadiyah \\ Banjarmasin, Banjarmasin, \\ Kalimantan Selatan, Indonesia \\ *email: \\ ridhaanwari90@gmail.com
}

\section{Kata Kunci: \\ Bahasa Indonesia \\ Soal \\ Ujian Nasional}

Keywords:

Indonesian Language

Questions

National Examination

\begin{abstract}
Abstrak
Pengabdian ini bertujuan untuk mempersiapkan mental dan kemampuan akademis siswa dalam menghadapi ujian nasional dan melatih siswa mengerjakan dan menjawab materi soal-soal Ujian nasionall secara benar. Metode yang digunakan dalam pengabdian ini adalah berbentuk ceramah, diskusi, tanya jawab, simulasi pembahsaan soal-soal ujian nasional, serta evaluasi. Sasaran dalam pengabdian ini adalah siswakelas XII di SMA Negeri 2 Banjarmasin yang terdiri dari 3 kelas yaitu XII Bahasa, XII Sos 6, dan XII Sos 5 yang jumlah rata-rata perkelas 30 orang. Hasil dari kegiatan pengabdian ini menunjukkan bahwa siswa kelas XII di SMA Negeri 2 Banjarmasin mendapatkan nilai yang baik dalam simulasi ujian nasional mata pelajran bahasa Indonesia. $80 \%$ telah mencapai kriteria ketuntasan dan lulus. $20 \%$ masih berada dalam ranah cukup dan perlu lebih banyak latihan lagi dalam menjawab soal-soal ujian nasional
\end{abstract}

\begin{abstract}
This service aims to prepare students' mental and academic abilities in facing national examination and to practice students to work on and answer the National Examination question's material correctly. The method used in this service is in the form of lectures, discussions, question and answer, simulation of national examination questions, and evaluation. The subject in this service is SMAN 2 Banjarmasin's students of XII grade which consists of 3 classes, namely XII Language programme, XII social programme 6, and XII Social programme 5 , which have an average number of 30 students for each class. The results of this service show that SMAN 2 Banjarmasin's students of XII grade get good grades in the national examination in Bahasa Indonesia's subject simulation. The percentage $80 \%$ shows they have reached the passing grade and they passed. The rate $20 \%$ is still insufficient domain, and they need more practice in answering national examination questions.
\end{abstract}

(C) 2019 The Authors. Published by Institute for Research and Community Services Universitas Muhammadiyah Palangkaraya. This is Open Access article under the CC-BY-SA License (http://creativecommons.org/licenses/by-sa/4.0/). DOI: https://doi.org// 0.33084/pengabdianmu.v4il.55I.

\section{PENDAHULUAN}

Ujian Nasional atau biasa disingkat UN adalah sistem evaluasi standar pendidikan dasar dan menengah secara nasional dan persamaan mutu tingkat pendidikan antar daerah yang dilakukan oleh Pusat Penilaian Pendidikan Depdiknas di Indonesia dengan berpedoman pada Undang-undang Republik Indonesia nomor 20 tahun 2003. Pada pasal 57 (ayat I) dijelaskan bahwa evaluasi dilakukan dalam rangka pengendalian mutu pendidikan secara nasional sebagai bentuk akuntabilitas penyelenggara pendidikan kepada pihak-pihak yang berkepentingan. Lebih lanjut, pada pasal 58 (ayat 2) dinyatakan bahwa evaluasi peserta didik, satuan pendidikan, dan program pendidikan dilakukan oleh lembaga yang mandiri secara berkala, menyeluruh, transparan, dan sistematik untuk menilai pencapaian standar nasional pendidikan (Susanti, 20I3).

Pro kontra dalam pelaksanaan Ujian Nasional terjadi disebabkan rasa kecewa masyarakat yang menilai pemerintah tidak konsisten, karena dengan Ujian Nasional tetap dijadikan sebagai faktor penentu kelulusan siswa ketimbang sarana pemetaan standar mutu pendidikan di Indonesia. Dari tahun ke tahun standar kelulusan terus meningkat, tetapi belum diimbangi dengan pemerataan fasilitas pendidikan di beberapa daerah. Hal ini secara tidak langsung membuat 
siswa mengalami kesulitan untuk untuk memenuhi target yang ada. Sehingga tidak sedikit siswa terpaksa harus mengulang, disebabkan nilainya kurang memenuhi standar (Mudlofir, 2013).

Ujian nasional merupakan sarana pemerintah untuk mengukur tingkat pendidikan di Indonesia. Oleh karena itu, kelulusan menjadi syarat mutlak yang harus dilalui oleh para siswa dalam tingkatan pendidikan mulai dari SD/SMP/SMA/Sederajat. Ujian nasioanl selalu dilaksanakan setiap tahun meski beragam reaksi yang timbul, mulai dari yang mendukung sampai yang mengharap dihentikan. Akan tetapi, nyatanya pelaksanaan ujian nasioal tetap selalu diselenggarakan (Kartowagiran \& Jaedun, 2016).

Selama ini SMA Negeri 2 Banjarmasin juga selalu rutin melaksanakan ujian nasioal. Sekolah sudah menyiapkan berbagai cara untuk menghadapi ujian nasioal, mulai dari simulasi, pengayaan pun terus dilakukan agar siswa mereka bisa lulus semua. Berdasarkan data dan wawancara dengan pihak sekolah, mereka menyatakan bahwa mata pelajaran bahasa Indonesia menjadi salah satu kendala para siswa untuk mencapai nilai yang tinggi. Hal ini disebabkan soal-soal ujian nasional mata pelajaran bahasa Indonesia yang rumit, selalu dimulai dengan teks-teks yang panjang, serta pilihan jawaban yang menyedikan piliahan jawaban benar dan hampir benar. Berbeda dengan mata pelajaran lain, matematika misalnya. Ujian nasional matematika itu bisa dijawab dengan pasti apabila siswa sudah bisa menghitungnya dengan benar (Noor \& Aman, 2015). Fakta lain juga menunjukkan sekolah belum pernah bekerjasama dengan berbagai perguruan tinggi terkait permasalahan ujian nasioal khususnya mata pelajaran bahasa Indonesia ini. Hal inilah yang membuat perlunya kerjasama perguruan tinggii dan sekolah berupaya melakukan peningkatan, pelatihan, dan pembahasan soal-soal bahasa Indonesia secara intensif (Wijayanti et al., 2016). Dilandasi dengan adanya keinginan untuk meningkatkan prestasi siswa dalam bidang akademik khususnya meningkatkan nilai output Ujian Nasional mata pelajaran Bahasa Indonesia bagi siswa kelas XII di SMA Negeri 2 Banjarmasin, maka perlu kiranya pihak sekolah melakukan kegiatan-kegiatan khusus yang mengarah kepada peningkatan prestasi siswa. Oleh karena itu, dosen pendidikan bahasa Indonesia UM Banjarmasin mencanangkan program pengabdian masyarakatnya ke sekolah-sekolah untuk membagikan sedikit keilmuan bahasa Indonesia terkait materi-materi ujian nasional tingkt SMA (Christella et al., 20I3).

Kegiatan pengabdian masyarakat ini berjudul "Pelatihan Penguasaan Soal UN Mata Pelajaran Bahasa Indonesia pada Siswa SMA Kelas XII SMA Negeri 2 Banjarmasin.” Materi pengabdian berupa Pendalaman Materi (PM) mata pelajaran Bahasa Indonesia. Model kegiatan pendalaman materi SMA Negeri 2 Banjarmasin, yaitu dengan cara melakukan pelatihan-pelatihan dalam menjawab dan mengerjakan soal-soal yang diprediksi akan keluar pada Ujian Nasional. Soal-soal ujian nasional diprediksi oleh guru-guru bahasa Indonesia bekerjasama dengan tim dosen pendidikan bahasa Indonesia UM Banjarmasin yang sudah berpengalaman mengajar.

\section{METODOLOGI}

Pelaksaan pengabdian masyarakat ini dilaksanakan selama bulan November 2018, bertempat di SMA Negeri 2 Banjarmasin. Sasaran dalam pengabdian ini adalah siswa kelas XII SMAN 2 Banjarmasin yang berjumlah 85 orang. Kegiatan ini dilaksanakan dalam bentuk ceramah/diskusi dan simulasi pembahasan soalsoal ujian nasional untuk mata pelajaran bahasa Indonesia. Aktivitas serta jadwal pengabdian disajikan dalam Tabel I.

Tabel I. Pelatihan Penguasaan Materi-Materi Ujian Nasional Bahasa Indonesia

\begin{tabular}{lllll}
\hline No & $\begin{array}{l}\text { Hari/ } \\
\text { tanggal }\end{array}$ & Kegiatan & Metode & Keterangan \\
\hline I & $\begin{array}{l}\text { Senin, 5 } \\
\text { November }\end{array}$ & $\begin{array}{l}\text { Mengurus } \\
\text { surat izin } \\
2018\end{array}$ & $\begin{array}{l}\text { pengabdian } \\
\text { dan surat }\end{array}$ & $\begin{array}{l}\text { Surat selesai } \\
\text { dalam waktu 2 } \\
\end{array}$ \\
& & hari \\
\hline
\end{tabular}




\begin{tabular}{|c|c|c|c|c|}
\hline & & $\begin{array}{l}\text { tugas dari } \\
\text { LP2M }\end{array}$ & & \\
\hline 2 & $\begin{array}{l}\text { Jumat, } 9 \\
\text { November } \\
2018\end{array}$ & $\begin{array}{l}\text { Tim } \\
\text { Pengabdian } \\
\text { mengantar } \\
\text { surat izin } \\
\text { ke SMA } \\
\text { Negeri } 2 \\
\text { Banjarmasin }\end{array}$ & - & $\begin{array}{l}\text { Sekolah } \\
\text { menyambut baik } \\
\text { kegiatan } \\
\text { pengabdian }\end{array}$ \\
\hline 3 & $\begin{array}{l}\text { Senin- } \\
\text { Rabu, 19- } \\
21 \\
\text { November } \\
2018\end{array}$ & $\begin{array}{l}\text { Tim } \\
\text { melakukan } \\
\text { pengabdian } \\
\text { di SMAN } 2 \\
\text { Banjarmasin }\end{array}$ & $\begin{array}{l}\text { Ceramah } \\
\text { Diskusi } \\
\text { Simulasi }\end{array}$ & $\begin{array}{l}\text { Menjelaskan } \\
\text { materi UN } \\
\text { bahasa Indonesia } \\
\text { Mendiskusikan } \\
\text { Menjawab soal } \\
\text { UN bahasa } \\
\text { Indonesia }\end{array}$ \\
\hline 4 & $\begin{array}{l}\text { Kamis, } 22 \\
\text { November } \\
2018\end{array}$ & $\begin{array}{l}\text { Evaluasi/ } \\
\text { perhitungan } \\
\text { nilai simulsi }\end{array}$ & & \\
\hline 5 & $\begin{array}{l}\text { Kamis- } \\
\text { Jumat, 29- } \\
30 \\
\text { November } \\
2018\end{array}$ & $\begin{array}{l}\text { Menyusun } \\
\text { laporan }\end{array}$ & & $\begin{array}{l}\text { Mengumpulkan } \\
\text { berkas dan } \\
\text { dokumentasi } \\
\text { pengabdian }\end{array}$ \\
\hline
\end{tabular}

\section{HASIL DAN PEMBAHASAN}

Hasil yang dicapai dalam kegiatan pengbdian ini adalah $80 \%$ siswa mencapai nilai yang baik dan dinyatakan lulus dalam perhitungan simulasi. Pelatihan ini sangat bermanfaat bagi para siswa kelas XII SMAN2 Banjarmasin yang telah mulai mampu menjawab dan mengerti tentang materi-mteri ujian nasional bahasa Indonesia. Namun, hasil ini belum maksimal karena masih ada siswa yng belum mencapai ketuntasan sebanyak 20\%. Oleh karena itu perlu dilakukan pengabdian selanjutnya yang berkesinambungan agar tujuan sekolah untuk meluluskan semua siswanya bisa tercapai.

Dari hasil kegiatn pengabdian pelatihan penguasaan soal UN bahasa Indonesia menunjukkan bahwa $80 \%$ siswa memahami dan memperoleh kelulusan dalam menjawab soal UN Bahasa Indonesia. Hasil ini menggambarkan bahwa para siswa memperoleh kategori yang baik dan sebagian masih perlu bimbingan lanjutan. Berikut beberapa gambar berjalannya proses pelatihan pengusaan dan simulasi menjawab soal-soal UN bahasa Indonesia.

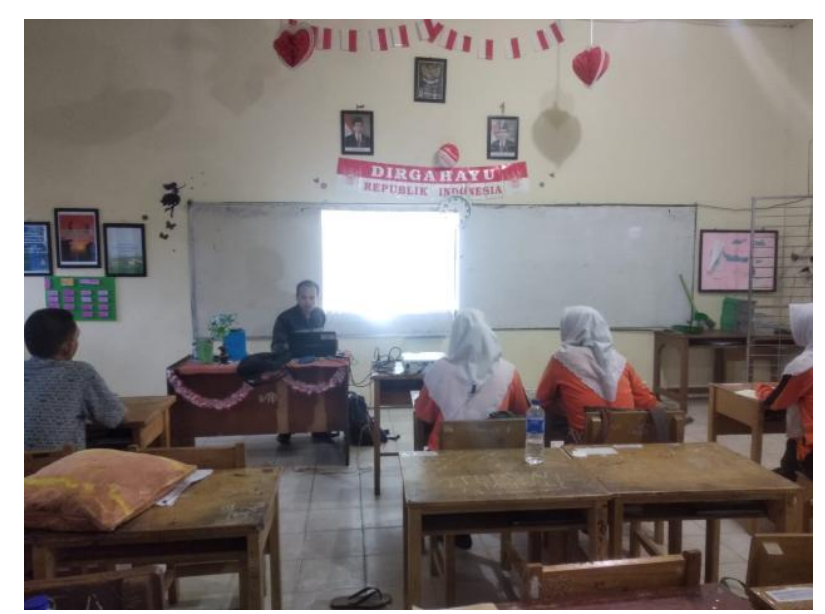

Gambar I. Penjelasan kepada para siswa

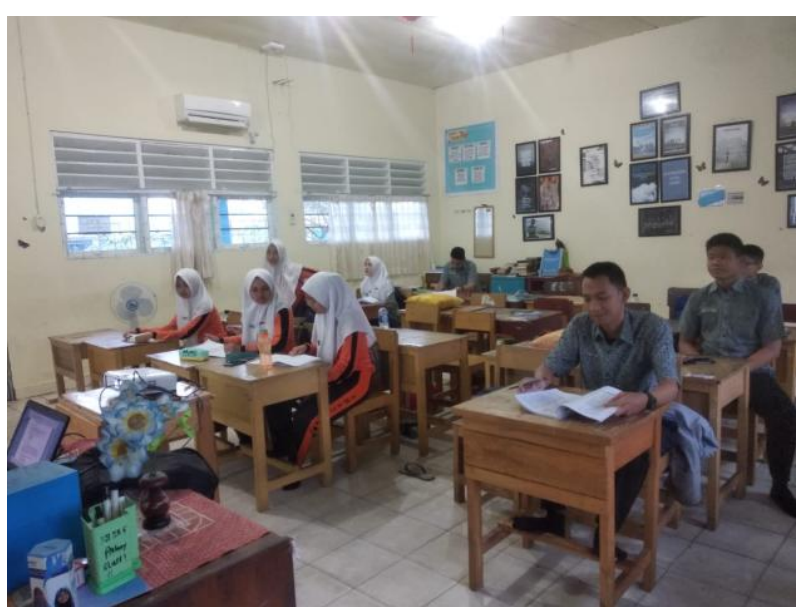

Gambar 2. Para siswa mengerjakan Soal UN Bahasa Indonesia

\section{KESIMPULAN}

Kegiatan pengabdian ini dalam bentuk pembahasan materi-materi soal ujian nasional mata pelajaran bahasa Indonesia dan bentuk simulasi menjawab soal-soal. Kegiatan ini mampu meningkatkan pemahaman siswa dalam memecahkan materi-materi terkait, serta mencapai hasil yang baik yaitu $80 \%$ siswa berhasil dan lulus simulasi. Kegiatan pengabdian ini masih memungkinkan untuk dilanjutkan pada kegiatan lain yang lebih variatif, dengan pengkajian yang lebih mendalam tentang materi-materi ujian nasional.

\section{REFERENSI}

Christella, Mustiningsih, \& Sunarni. 2013. Persepsi Tentang Jam Pelajaran Tambahan Hubungannya dengan Prestasi Belajar Siswa 
Kelas Unggulan dan Reguler. Kelola. 24(2): 100-107.

Kartowagiran, B. \& Jaedun, A. 2016. Model Asesmen Autentik untuk Menilai Hasil Belajar Siswa Sekolah Menengah Pertama (SMP): Implementasi Asesmen Autentik di SMP. Jurnal Penelitian dan Evaluasi Pendidikan. 20(2):|3|-|4|.

Mudlofir, A. 2013. PendidikanKarakter: Konsep dan Aktualisasinya dalam Sistem Pendidikan Islam. Nadwa: Jurnal Pendidikan Islam. 7(2):229-363.

Noor, W.N. \& Aman. 20I5. Evaluasi Penyelenggaraan Latihan Ujian Nasional Bahasa Inggris SMA Swasta Ex-RSBI. Jurnal Penelitian dan Evaluasi Pendidikan. 19(2):217-229.

Susanti, R. 2013. Analisis Kinerja Performance Ujian Nasional Tahun 2013. Jurnal Teknologi Pendidikan. 2(I):77-88.

Wijayanti, S.H., Budhayanti, C.I.S., \& Darmayanti, S. Uji Coba Ujian Nasional di Madrasah Ibtidaiyah At Taqwa 44, Kecamatan Babelan, Desa Pantai Hurip, Bekasi. JAM (Jurnal Abdi Masyarakat). 2(I):52-58. 